\title{
Do infants have agency? - The importance of control for the study of early agency
}

\author{
Florian Markus Bednarski ${ }^{\text {a,b,c, }}$, Kristina Musholt ${ }^{\text {b,c }}$, Charlotte Grosse Wiesmann ${ }^{a}$ \\ ${ }^{a}$ Minerva Fast Track Research Group Milestones of Early Cognitive Development, Max Planck Institute for Human Cognitive and Brain Sciences, \\ Leipzig, Germany \\ ${ }^{\mathrm{b}}$ Department of Philosophy, Leipzig University, Germany \\ ${ }^{\mathrm{c}}$ Leipzig Research Center for Early Child Development, Leipzig University, Germany
}

\section{A R T I C L E I N F O}

\section{Keywords:}

Agency

Infancy

Motor control

Multi-sensory contingency

Mobile paradigm

\begin{abstract}
A B S T R A C T
Questions about infants' development of agency have been a topic of great interest for developmental psychology for many years. The central claim of our review is that agentic control is a necessary feature of minimal agency. We review influential experimental paradigms on infants' agency which have predominantly focused on infants' detection of multi-sensory contingencies (e.g., the mobile paradigm). We argue that these paradigms show infants' ability to integrate multi-sensory information and learn reinforced movements, but do not test whether infants have agentic control over these movements. We further argue that, without a measure of agentic control, it cannot be conclusively shown whether the movements produced by infants reflect mere automatic responses or are indeed evidence of infants'controlled actions. Finally, based on the criterion of agentic control, we derive concrete experimental suggestions for a test of infants' minimal agency.
\end{abstract}

\section{Introduction}

The question to what extent preverbal infants are agents has been one of the central debates of developmental research and theory. By developing the ability to act, infants' interaction with the environment becomes more purposeful and rewarding. They are not simple responders anymore but can actively participate in and thus shape their social and non-social environments (Piaget, 1950; Russell, 1996; Gibson, 1988; Rochat \& Striano, 2000).

In the following we argue that developmental studies on detection of contingency in movement do not test for infants' agentic control as a criterion for minimal agency. Without a measure of agentic control, however, it is difficult to distinguish actions that are controlled by the infant from other movements that just happen to them and thus to know whether infants really are agents. We argue that in order to address questions on the development of agency in preverbal infants, studies should assess infants' control over the flexible adaptation of their movements. Thus, at the end of this review we propose a paradigm that specifically measures agentic control.

\footnotetext{
* Corresponding author at: Minerva Fast Track Research Group Milestones of Early Cognitive Development, Max Planck Institute for Human Cognitive and Brain Sciences, Leipzig, Germany.

E-mail address: fteichmann@cbs.mpg.de (F.M. Bednarski).
} 


\section{The theory of agency}

What is agency? On the face of it, the answer to this question is as simple as it gets: agency is the ability to act. Hence, an agent is a being that is able to act (Mele, 2000; Pacherie, 2007; Hyman, 2015). However, this definition leads directly to the Problem of Action, which was introduced by Harry Frankfurt in 1978: "The Problem of Action is to explicate a contrast between what an agent does and what merely happens to him, or between the bodily movements that he makes and those that occur without his making them" (Frankfurt, 1978, p.157). Developmental science has to address this very problem in order to answer the question about agency in nonor preverbal individuals. According to Frankfurt, the difference between an agent doing something and something happening to an agent is that in the former case the agent is in control over what he does. Importantly, agency does not just 'pop-up' in ontogenetic development, rather agency develops over time. This development most likely includes several intermediate stages. The task of developmental psychology is to explicate the steps along which this development unfolds. We argue that possession and exercise of agentic control over bodily movements is a critical step in this development. ${ }^{1}$ This step allows us to differentiate movements from actions, that is, something which is merely happening to the infant from a movement that is initiated and controlled by the infant. Infants who possess and exercise agentic control can learn from and participate in their environment not only by chance but in a structured way. This new way to interact with their environment will allow them to form predictions and develop intentions for action. Thus, possession and exercise of agentic control is the first significant step for infants to become intentional agents.

The question then is when does the transition from mere movement (something happening) to action (doing something) occur. In other words, when does the infant take control over their movements?

Imagine a little girl visiting the doctor. To assess the girl's healthy development, the doctor wants to test the patellar tendon reflex. The patellar tendon reflex is a quick and fast kicking movement of the leg triggered by a slight knock with a reflex hammer to the knee. Hence, upon a slight strike with a reflex hammer to the patellar tendon, the girl's leg will automatically kick. However, imagine the girl sees the doctor picking up the reflex hammer, becomes afraid and decides to kick him. Just as the doctor aims at her knee, she raises her leg. The movement described in this story is indistinguishable from an instance of the patellar tendon reflex. This is in fact the case for all reflexes: if observed from the outside it is nearly impossible to distinguish controlled kicking, grasping and blinking from their reflex counterparts. Nonetheless, there is an obvious difference between the two movements: in our story the girl kicked intentionally, while in the reflex case it causes the girl's leg to kick. While an automatic reflexive movement outside of the girl's control can hardly classify as the girl's action, her active kick is a classic example of it. An ambiguous case occurs when the girl throws a tantrum and kicks the doctor out of anger. ${ }^{2}$ In this case it is unclear whether the girl exercises control over her leg motion or the leg kicking merely reflects an emotional expression of her anger, similar to other bodily expressions of emotional states. Thus, by merely observing the movements, we cannot know whether the girl was in control.

This story shows that a necessary feature of an action is agentic control. An action can therefore be defined as a controlled bodily movement (Shepherd, 2014; Fridland, 2017; Buehler, 2019). Minimal agency then is the possession of the ability to exert agentic control over one's bodily movements, and as this example illustrates, it is a necessary condition:

A being is a minimal agent if and only if it is able to possess and exert agentic control over its bodily movements.

Before infants take over agentic control, they are able to emit integrated activity such as operant or reflexive movements (e.g. palmar grasp reflex, non-nutritive sucking). Reflexes are not controlled by the infants, however for operant movements we cannot know without conducting specific tests for agentic control. Operant reinforced movements occur because of a reciprocal relation between movement and reward. If those movements cannot be suppressed or flexibly adapted by infants, they are mere movement and not action. Thus, we can only know for sure whether a movement constitutes an action, if we can measure agentic control of the infant over the movement in question. As mentioned before, minimal agency is significant because it enables infants to explore and learn in a structured and self-determined way from their movements and the environment. Before infants develop the ability to take over control, their learning and exploration is dependent on affordances of the environment. Those affordances either trigger elicited movement or infants produce emitted movement in response. However, when infants are able to possess and exert agentic control their learning and exploration becomes more purposeful and rewarding.

Having agentic control over one's bodily movements means being able to flexibly adapt them in response to changing internal and external factors (Shepherd, 2014; Fridland, 2017; Buehler, 2019). Defining agentic control in this way is defining it by stating what agentic control allows an agent to do. This allows for an operationalization in non-verbal experimental paradigms including the developmental context. ${ }^{3}$

Importantly, here we do not attempt to say anything about the cognitive processes involved in the possession and exertion of agentic control. We argue that a being is a minimal agent when it is able to flexibly adapt its movement to changing internal and external factors and thereby displays agentic control over its bodily movements. Two components of our definition require further explication. Being able to flexibly adapt one's actions allows a minimal agent to interfere with an initiated action program at will. This is necessary because internal and external factors might change after an action program has been initiated. Changes in internal and

\footnotetext{
${ }^{1}$ Possession of agentic control refers to the capacity for control, while exercise of agentic control refers to the use of agentic control in an event. Once infants have developed agentic control, they generally possess the capacity for control and can exercise it when required.

2 We thank an anonymous reviewer for raising this point.

3 Another way of defining control would be by stating how control works. This would require reference to the individual cognitive processes involved in the employment of control (Fridland, 2014; Wu, 2011), which would, however, make an operationalization in non- and preverbal individuals difficult.
} 
external factors include changes of a minimal agent's action goal or execution plan as well as changes in the environment that might or might not have an effect on the initiated action program. Flexibility in response to such changes is required for a movement to be a controlled action because the mere observation of stimulus - movement - stimulus interactions might result from a conditioned motor response or reflex. Newborns, for example, are born with a strong palmar grasping reflex. As soon as something touches their palm, they close their hand tightly. However, they cannot flexibly adapt this grasping movement to changing circumstances. ${ }^{4}$

Observing a flexibly controlled movement response to a stimulus, however, will reveal if the event is a controlled action or a mere movement. For example, in the story about the girl, her mother might change internal factors by telling her not to kick the doctor, and because the girl possesses agentic control over her movements she can abstain from her action. To clarify, it is not her mother's intervention that puts the girl in a position to take over control. The intervention merely unveils the girl's ability to do so.

In sum, reflexes and conditioned behaviors are not controlled actions. However, the resulting observable movements are indistinguishable from controlled actions. For example, in many circumstances, it is impossible to tell whether someone kicking their leg is in control of this behavior or not. However, agentic control can be uncovered through a change of internal or external circumstances. For instance, the girl in our example is able to take control over her movement upon being asked to do so by her mother. In the following, we will argue that most agency paradigms in developmental psychology have neglected agentic control in infants' development of agency so far. We will conclude by proposing a further paradigm to address this oversight.

\section{Theoretical foundations of empirical approaches to infant agency}

In contrast to the theoretical perspective explained above, empirical approaches to infant agency have emphasized infants' ability to register their own efficacy in the world as a criterion for agency (Russell, 1995; Piaget, 1950; Gibson, 1988). Gibson and Adolph, for example, argue that "Infants notice whether their actions have environmental consequences and use the resources available to them to maintain desired effects" (Gibson \& Adolph, 1992, p. 120). ${ }^{5}$ The hypothesis is that infants from about 3 months onwards are able to link observed events in the environment with their own movement and thereby deduce whether the event was caused by their own movement or an external factor.

Building on this tradition, in current developmental studies on agency, infants' ability to detect contingency in action is frequently used as a measure for infants' agency. These studies have tested infants' ability to detect a contingency between self-produced limb movements and visual percepts of such movements. These approaches can be divided into two groups of experimental paradigms. The first group has been interested in infants' passive observational capacities; we refer to these paradigms as passive contingency paradigms. The second group is interested in infants' active behavior and learning about the environment in settings where they actively drive sensory-motor contingencies; we refer to these paradigms as active contingency paradigms. Both paradigm types rely on multi-sensory contingencies mainly between visual stimuli and bodily movements of the infant. The ability to detect such a contingency is often interpreted as infants' realization of their own efficacy, which has also been referred to as them having a sense of agency (Blakemore \& Frith, 2003; Bayne \& Pacherie, 2007; Synofzik et al., 2008). According to this view, infants are thought to display a sense of agency when they realize that their actions cause effects in the world around them (Zaadnoordijk et al., 2019). This view on infant agency may also be called the reflective view, as it focuses on the infants' own experience of their actions and presupposes their ability to reflect on their own behavior (cf. Hommel, 2015; Sokol et al., 2015). Investigating infants' possession of a sense of agency thus is fundamentally an investigation of a phenomenological or experiential dimension of agency. This is one way of referring to the experience of agency, others have referred to this question with a different terminology (cf. Braun et al., 2018, Jacquey et al., 2020, Sen and Gredebäck, 2021).

However, note that phenomenological properties are very difficult to measure in non-verbal participants. What's more, we take it that developmental psychology will to a certain extent always remain in the dark about the precise cognitive processes in infants. Thus, terminology that alludes to adult-like cognitive abilities should be used with caution.

A number of studies indeed indicate that multimodal integration successfully works early on in infancy (Bremner et al., 2008, 2012; Thomas et al., 2017; Begum Ali et al., 2021). However, this does not necessarily entail infants' ability to consciously register their own efficacy. The mere observation of bodily movements does not allow us to infer conclusions about the infants' experience. The latter can only be conclusively supported by means of verbal confirmation, which is not possible in the preverbal population of 3- to 10-monthold children typically tested in the described contingency paradigms. Hence, contingency paradigms cannot really provide us with information regarding infants' sense of agency in the phenomenological sense.

Reoccurring self-produced limb movements in response to a reinforcing visual stimulus (e.g., a jiggling mobile) are however an information source for the infant. Infants learn from perceiving a contingent relation between proprioceptive information about bodily states and visual information about the environment (Gergely and Watson, 1999). Further, this reciprocal motion can be viewed as emitted integrated activity and thus can be described as infants partaking in active and passive contingency paradigms. Yet the observed movements do not directly convey information on infants' agentic control. Gibson defined agency as the self in control; she

\footnotetext{
${ }^{4}$ It has been argued that some reflexes might not be as rigid as initially assumed. There is some evidence that infants exert effort to produce neonatal movements (e.g. non-nutritive sucking and extended arm movements) in a flexible manner (von Hofsten, 1982; van der Meer et al., 1995; Craig \& Lee, 1999). These findings indicate that visual control of movements develops from birth onwards. How subordinated to the infants' will these processes are remains an open question. A test indicating flexibility in those behaviors, which cannot be explained by hard wired sensory motors loops, is necessary to determine whether infants are in control or not.

${ }^{5}$ We thank an anonymous reviewer for directing us to Gibson's work.
} 
emphasized that action is neither reflex nor instrumental conditioning. Action, in her work, is characterized by the occurrence of intermodal information about the self and the environment. "Control of an observable event by one's own action is the essence of agency, eventually exercised, in elaborate and strategic ways by skilled planners." (Gibson, 1994, p. 72). Thus, following Gibson we emphasize that measuring agentic control is necessary for investigating infants' development of agency.

In the next two sections, we will review passive and active contingency paradigms in more detail. We aim to demonstrate that although infants learn from environmental contingencies and this process is possibly a first step for the development of agency, infants do not show agentic control over movements produced in those experimental situations. This is because the paradigms employed so far lack a measure of infants' agentic control when detecting or reacting to contingencies. We will argue that only if we can show infants' flexible agentic control over their movements in reaction to changing contingencies in these situations can we distinguish controlled actions from other bodily movements such as conditioned responses or expressions of emotion. Without a measure of agentic control, it cannot be conclusively shown whether an infant is a minimal agent or not.

\section{Passive contingency paradigms}

The first group of paradigms used to investigate infants' agency focuses on infants' capacities to detect multi-sensory contingencies when passively observing their own body movements, here referred to as passive contingency paradigms. The main measure in passive contingency paradigms is infants' looking behavior, for example their visual preference for either temporally synchronous or asynchronous displays of the child's own bodily movement. The aim is to investigate whether infants detect this multi-sensory visuoproprioceptive contingency by showing that they distinguish between congruent and incongruent displays of their own bodily movements.

In a typical passive contingency paradigm, infants view two video screens, one of which displays a live feed of their own limb movements. The other screen shows a manipulated version of this video where their limb movement appears to be either delayed, rotated or visually edited. Infants' reaction to these displays is coded, typically in the form of their looking behavior. The general principle of these studies has remained the same over the years (see Fig. 1).

A seminal example of such a passive contingency paradigm was conducted by Bahrick and Watson in 1985. In Bahrick and Watson's experiment, 5-month-old infants were seated in front of two video screens. A camera recorded their legs from an ego-perspective. One of the screens displayed a contingent live feed from the camera while the other played a previously recorded non-contingent video from a peer. In all three conditions of the experiment infants showed a preference for the non-contingent display. Thus, if 3- to 5month-old infants perceive a distinct sensory input (e.g., visual percept of a leg moving) simultaneously to another distinct sensory

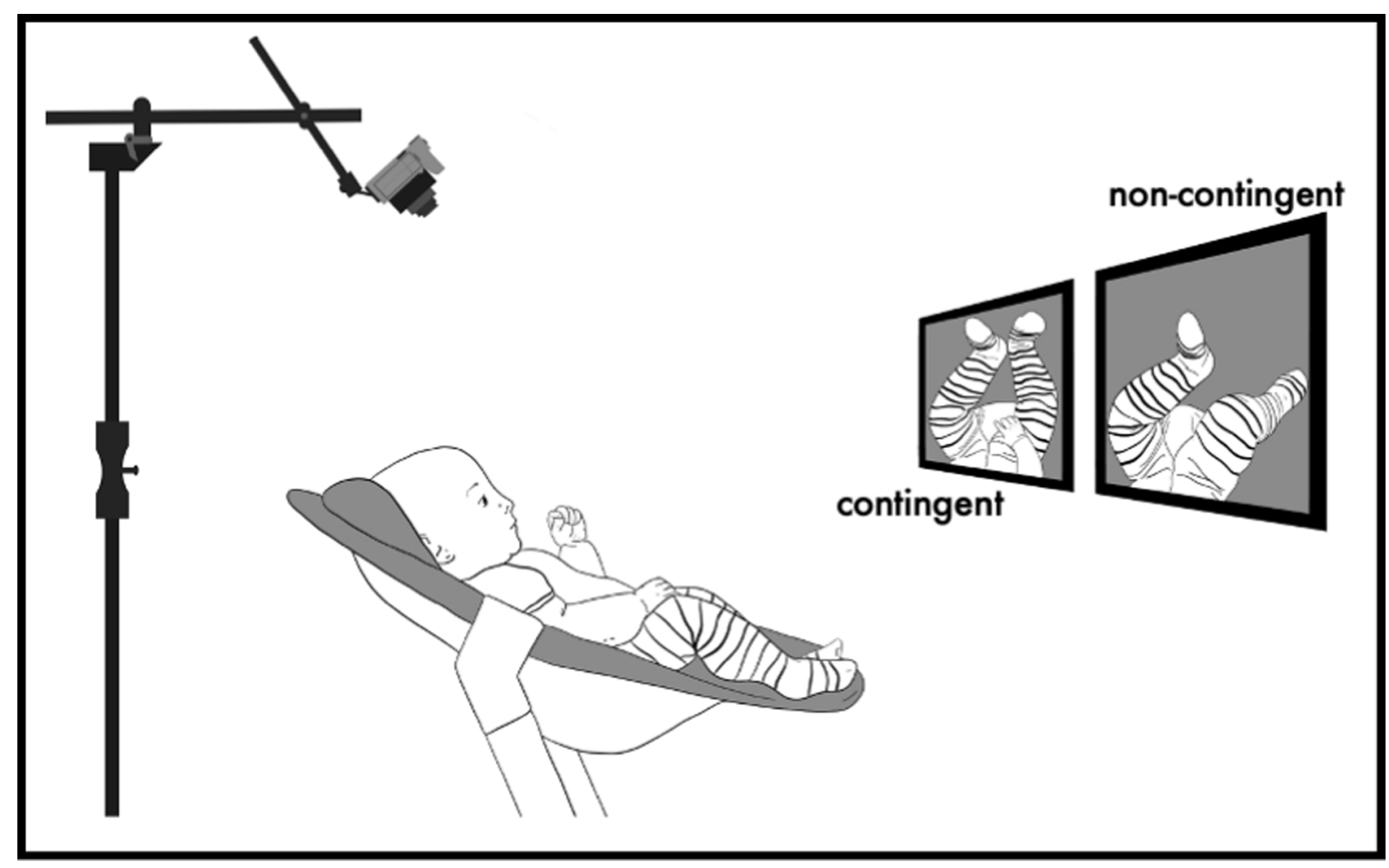

Fig. 1. Sketch of a typical setting of a passive contingency paradigm. The infant views two screens at the same time. One is displaying a contingent video of the infant's legs while the other is displaying a non-contingent (e.g., temporally delayed) video of the infant's legs. Infants looking time at each of the screens is coded. 
Table 1

Overview Passive Contingency Paradigms.

\begin{tabular}{|c|c|c|c|c|c|c|}
\hline Author & Year & Description & $\mathrm{N}$ & $\begin{array}{l}\text { Age }(\mathrm{m}- \\
\text { month; } \mathrm{h} \text { - } \\
\text { hours) }\end{array}$ & Main findings & $\begin{array}{l}\text { Effect Size/ } \\
\text { Cohen's d* }\end{array}$ \\
\hline \multirow[t]{4}{*}{$\begin{array}{l}\text { Bahrick \& } \\
\quad \text { Watson }\end{array}$} & \multirow[t]{4}{*}{1985} & $\begin{array}{l}\text { Exp 1: Preferential looking to either live video or video recording of a } \\
\text { peer. Both videos filmed from an ego-perspective on the legs. }\end{array}$ & 20 & $5 \mathrm{~m}$ & Infants look longer to non-contingent video of a peer. & \multirow[t]{4}{*}{$\begin{array}{l}\text { ic - incalculable } \\
\text { with reported data }\end{array}$} \\
\hline & & Exp 2: Adaptation of Exp. 1 by occlusion of sight to own legs. & 20 & $5 \mathrm{~m}$ & Infants use proprioceptive information for discrimination. & \\
\hline & & $\begin{array}{l}\text { Exp 3: Adaptation of Exp. } 1 \text { by switch to a recording of the participants } \\
\text { own legs and not the legs of a peer. }\end{array}$ & 20 & $5 \mathrm{~m}$ & Infants do not use visual characteristics of own legs for discrimination. & \\
\hline & & Exp 4: Same as Exp. 2 but with 3 months-old participants. & 20 & $3 \mathrm{~m}$ & Infants show less preference for either video. & \\
\hline Rochat \& & \multirow[t]{6}{*}{1995} & $\overline{\operatorname{Exp} 1}$ : Preferential looking to either observer view (non-contingent, NC) & 10 & $3 \mathrm{~m}$ & Infants look longer at the observer view than at the ego view video. 3 & 2.81 \\
\hline \multirow[t]{5}{*}{ Morgan } & & $\begin{array}{l}\text { or ego view (contingent, C) live video of own legs. Both videos have } \\
\text { different spatial orientation and different directionality of movement. }\end{array}$ & 10 & $4-5 \mathrm{~m}$ & months-old infants show a larger effect than 4-5 months-old infants. & 1.362 \\
\hline & & Exp 2: Preferential looking to either ego view (C) or reversed ego view & 10 & $3 \mathrm{~m}$ & Infants look longer at the reversed ego view than at the ego view & 0.691 \\
\hline & & $\begin{array}{l}\text { (NC) live video of own legs. Both videos have the same spatial orientation } \\
\text { but different directionality of movement. }\end{array}$ & 10 & $4-5 \mathrm{~m}$ & $\begin{array}{l}\text { video. Directionality of movement (identical or reversed motion) is } \\
\text { sufficient to produce the preferential looking effect. }\end{array}$ & 0.837 \\
\hline & & Exp 3: Preferential looking to either reversed observer view (NC) or ego & 10 & $3 \mathrm{~m}$ & Infants show no significant preference for either video. Thus, & 0.343 \\
\hline & & $\begin{array}{l}\text { view (C) live video of own legs. Both videos have the same directionality } \\
\text { of movement but different spatial orientation. }\end{array}$ & 10 & $4-5 \mathrm{~m}$ & $\begin{array}{l}\text { directionality of movement is necessary and sufficient to produce the } \\
\text { preferential looking effect. }\end{array}$ & 0.681 \\
\hline \multirow[t]{3}{*}{ Schmuckler } & \multirow[t]{3}{*}{1996} & $\begin{array}{l}\text { Exp 1: Preferential looking to either live video of own right hand } \\
\text { exploring a hidden toy in a box (C) or recorded video of the same action } \\
\text { from a peer (NC), both from an ego perspective. }\end{array}$ & 18 & $5 \mathrm{~m}$ & $\begin{array}{l}\text { Infants show a significant preference for the non-contingent video. } \\
\text { Further, infants are able to discriminate hand motion by intermodal } \\
\text { visual proprioceptive integration. }\end{array}$ & 1.0 \\
\hline & & $\begin{array}{l}\text { Exp 2: Preferential looking as in experiment } 1 \text { but with left-right reversal } \\
\text { of both videos (own ego perspective and peer ego perspective). }\end{array}$ & 22 & $5 \mathrm{~m}$ & Infants show no significant preference for either video. & $\begin{array}{l}\text { No significant } \\
\text { effect. }\end{array}$ \\
\hline & & $\begin{array}{l}\text { Exp 3: Preferential looking as in experiment } 1 \text { but both videos filmed from } \\
\text { below the palm. On the screen infants viewed either their own hand or } \\
\text { the hand of a peer exploring a toy with their wrist at the top of the screen } \\
\text { and their fingers pointing downwards. }\end{array}$ & 20 & $5 \mathrm{~m}$ & Infants show a significant preference for the non-contingent video. & 0.69 \\
\hline \multirow{6}{*}{$\begin{array}{l}\text { Schmuckler \& } \\
\quad \text { Fairhall }\end{array}$} & \multirow[t]{6}{*}{2001} & Exp 1: Preferential looking to either ego view (C) or ego view of a peer & 24 & $5 \mathrm{~m}$ & Infants showed a significant preference for the non-contingent video. & 0.596 \\
\hline & & $\begin{array}{l}\text { (NC) live video of own legs. Absence of morphological characteristics due } \\
\text { to use of point-light display (infants wore socks with } 6 \text { dots of fluorescent } \\
\text { color by using black light the video only consisted of moving dot } \\
\text { resembling the motion of the legs). }\end{array}$ & 24 & $7 \mathrm{~m}$ & $\begin{array}{l}\text { Presumably because only point-light information for knee, ankle and } \\
\text { toes was provided the effect was inconclusive across different } \\
\text { measures. }\end{array}$ & 0.803 \\
\hline & & Exp 2: Preferential looking comparable to experiment one, but with 18 & 24 & $5 \mathrm{~m}$ & Infants showed a significant preference for the non-contingent video. & 0.355 \\
\hline & & $\begin{array}{l}\text { dots composing the point-light information. Not only knee, ankle and toes } \\
\text { but also off-joint placement. }\end{array}$ & 24 & $7 \mathrm{~m}$ & $\begin{array}{l}\text { Although, the effect for the 7-month-olds is larger there was no main } \\
\text { effect found for age. }\end{array}$ & 1.362 \\
\hline & & Exp 3: Preferential looking comparable to experiment two ( 18 dots), but & 24 & $5 \mathrm{~m}$ & Infants showed no preference for either video. & No significant \\
\hline & & observer perspective instead of ego perspective for both videos. & 24 & $7 \mathrm{~m}$ & & effect. \\
\hline \multirow[t]{2}{*}{ Schmuckler } & \multirow[t]{2}{*}{2007} & $\begin{array}{l}\text { Exp 1: Preferential looking to either a live video of a mobile moved by the } \\
\text { participating infants' legs (C) or a recorded video of the same action from } \\
\text { a peer (NC). Two trials each } 1 \text { min were conducted. }\end{array}$ & 20 & $5 \mathrm{~m}$ & $\begin{array}{l}\text { Infants showed no conclusive preference for either video. In trial } 1 \mathrm{NC} \\
\text { was preferred and in trial } 2 \mathrm{C} \text { was preferred. }\end{array}$ & $\begin{array}{l}\text { No significant } \\
\text { effect. }\end{array}$ \\
\hline & & $\begin{array}{l}\text { Exp 2: Preferential looking comparable to experiment one, but with the } \\
\text { connection to the mobile being diverted via pulley apparatus to increase } \\
\text { temporal delay. }\end{array}$ & 20 & $5 \mathrm{~m}$ & $\begin{array}{l}\text { Infants showed no preference for either video. This result suggests that } \\
\text { disruption of spatial and temporal contingency diminishes infants } \\
\text { intermodal visual-proprioceptive perception. }\end{array}$ & $\begin{array}{l}\text { No significant } \\
\text { effect. }\end{array}$ \\
\hline
\end{tabular}


Table 1 (continued)

\begin{tabular}{|c|c|c|c|c|c|c|}
\hline Author & Year & Description & $\mathrm{N}$ & $\begin{array}{l}\text { Age }(\mathrm{m}- \\
\text { month; h - } \\
\text { hours) }\end{array}$ & Main findings & $\begin{array}{l}\text { Effect Size/ } \\
\text { Cohen's d* }\end{array}$ \\
\hline \multirow[t]{3}{*}{ Zmyj et al. } & \multirow[t]{3}{*}{2011} & $\begin{array}{l}\text { Exp 1: Preferential looking to either visual and tactile contingent or non- } \\
\text { contingent video. Videos were recorded in advance and displayed infants' }\end{array}$ & 32 & $7 \mathrm{~m}$ & \multirow[t]{2}{*}{$\begin{array}{l}\text { 10-months-olds showed a significant preference for the contingent } \\
\text { video. }\end{array}$} & $\begin{array}{l}\text { No significant } \\
\text { effect. }\end{array}$ \\
\hline & & $\begin{array}{l}\text { legs from an ego-perspective being stroked by two fingers from the knee } \\
\text { to the ankle. While viewing the two videos participants legs were stroked } \\
\text { contingent to either the left or the right video. }\end{array}$ & 32 & $10 \mathrm{~m}$ & & 0.769 \\
\hline & & $\begin{array}{l}\text { Exp 2: Preferential looking comparable to experiment one, but instead of } \\
\text { lifelike puppet legs wooden blocks were used to record the stimuli videos. }\end{array}$ & 32 & $10 \mathrm{~m}$ & $\begin{array}{l}\text { Infants showed no preference for either video. This result suggests that } \\
\text { morphological features are necessary for visual-tactile contingency } \\
\text { detection. }\end{array}$ & $\begin{array}{l}\text { No significant } \\
\text { effect. }\end{array}$ \\
\hline \multirow[t]{2}{*}{ Filippetti et al. } & \multirow[t]{2}{*}{2013} & $\begin{array}{l}\text { Exp 1: Sequential preferential looking to either visual and tactile } \\
\text { contingent or non-contingent video. Videos were recorded in advance } \\
\text { and displayed a five months old infants' face being stroked with a } \\
\text { paintbrush on the cheek. Stroking applied to the participating infants was } \\
\text { either synchronous/contingent (C) or asynchronous/non-contingent } \\
\text { (NC) to the stroking in the video. For the participants it looked as if they } \\
\text { were looking in a mirror. }\end{array}$ & 20 & $45.2 \mathrm{~h}$ & $\begin{array}{l}\text { Infants showed a significant difference between contingent and non- } \\
\text { contingent stimuli. }\end{array}$ & 0.341 \\
\hline & & $\begin{array}{l}\text { Exp 2: Sequential preferential looking comparable to experiment one, but } \\
\text { both videos now inverted. Infants head is now displayed upside down. }\end{array}$ & 20 & $49.8 \mathrm{~h}$ & $\begin{array}{l}\text { Infants showed no significant difference between contingent and non- } \\
\text { contingent stimuli. }\end{array}$ & $\begin{array}{l}\text { No significant } \\
\text { effect. }\end{array}$ \\
\hline Filippetti et al. & 2015 & $\begin{array}{l}\text { Sequential preferential looking to either visual and tactile contingent or } \\
\text { non-contingent video. Videos were recorded in advance and displayed an } \\
\text { infant's face either being stroked on the cheek or forehead with a } \\
\text { paintbrush. In the contingent condition (C) participants were stroked in } \\
\text { the same position as in the video, in the non-contingent condition (NC) } \\
\text { participants were stroked in the opposite position. }\end{array}$ & 20 & $40.45 \mathrm{~h}$ & $\begin{array}{l}\text { Infants preferred looking at the contingent video. This result shows } \\
\text { that not only temporal but also spatial cues influence detection of } \\
\text { visual-tactile contingency from birth. }\end{array}$ & 0.744 \\
\hline Filippetti et al. & 2016 & $\begin{array}{l}\text { Preferential looking to either visual and tactile contingent or non- } \\
\text { contingent video. Videos were recorded in advance and displayed a five } \\
\text { months old infants' face being stroked with a paintbrush on the cheek. } \\
\text { The participating infants face was stroked in the same pattern while } \\
\text { watching the recorded video on a split screen. One side being contingent } \\
\text { (C) to the felt touch, the other side being } 3 \mathrm{~s} \text { delayed (NC) to the felt } \\
\text { touch. }\end{array}$ & 14 & $5 \mathrm{~m}$ & Infants preferred looking at the contingent video. & 1.28 \\
\hline
\end{tabular}

* All effect sizes calculated according to Lakens (2013). 
input (e.g., proprioceptive percept of a leg moving), they are able to detect a match or mismatch between these two modally distinct sensory inputs. Bahrick and Watson argued that the detection of these multisensory contingencies shows an underlying capacity for the development of self-perception.

Other researchers put forward richer interpretations of passive contingency paradigms, linking them to self-awareness and agency. Philippe Rochat might be one of the strongest advocates for the view that passive contingency not only shows the development of multisensory perception but is an instance of perceiving oneself. In another influential passive contingency study, 3- to 5-month-old infants were seated in front of a split screen with a live feed of their legs from an ego-perspective (contingent) and an observer perspective (non-contingent) (Rochat \& Morgan, 1995). Infants' preference to look at their leg movements on either of the two live feeds was analyzed. In further conditions, Rochat and Morgan contrasted the ego-perspective live feed with versions in which its spatial orientation or timing had been manipulated. Infants looked significantly longer and showed more leg movements when observing the non-contingent videos. These findings were interpreted as evidence for infants' early preconceptual agency. More specifically, Rochat and Morgan argued that this shows that 3- to 5-month-olds were able to identify their own leg motion when presented with a congruent and incongruent source of information. According to Rochat (2010), infants have a pre-reflective and implicit embodied self-awareness from birth on. Through self-produced action, infants receive proprioceptive information which by its nature is self-specifying. Following this assumption, Rochat and Striano (2000) concluded the following about contingency learning: "This remarkable instrumental learning capacity testifies to the fact that, early on, infants manifest a sense of themselves as an agent in the environment, an important aspect of the (implicit) ecological self' (Rochat \& Striano, 2000, p. 519). Similar claims have been derived from comparable experiments with different timing of the congruency (Hiraki, 2006; Zmyj et al., 2011), spatial orientation of one's own body display (Rochat \& Morgan, 1995; Schmuckler, 1996; Rochat et al., 1997) or morphology of the displayed body parts (Rochat et al., 1997; Schmuckler \& Fairhall, 2001; see Table 1 for an overview of studies using passive contingency paradigms).

However, critiques of these interpretations have pointed out that a mere visual preference for, or detection of, multi-sensory contingency does not require the infant to understand that the multi-sensory contingent stimulus constitutes their own body, nor that they are the ones causing this multi-sensory contingency with their own leg movements (Bremner et al., 2008). Thus, passive contingency paradigms do not indicate agency or a sense of self, although they might indicate underlying capacities that provide the foundation for the development of agency and self-awareness (Bremner, 2017; Hadders-Algra, 2010; Thelen et al., 1996).

While passive contingency paradigms indeed demonstrate infants' powerful abilities to distinguish visual-proprioceptive contingent from non-contingent stimuli, this does not yet show that infants understand that these movements are related to themselves, nor that their own movements cause an effect in the perceptual environment. Moreover, infants' abilities to initiate and control these movements are not measured in those paradigms. Thus, passive contingency paradigms do not allow conclusions about agentic control on the part of the infant. The infant's gaze is merely drawn from one screen to the other and the time spent fixating the stimuli is measured. Furthermore, throughout the experiment external factors remain constant. The infant views two screens which show two

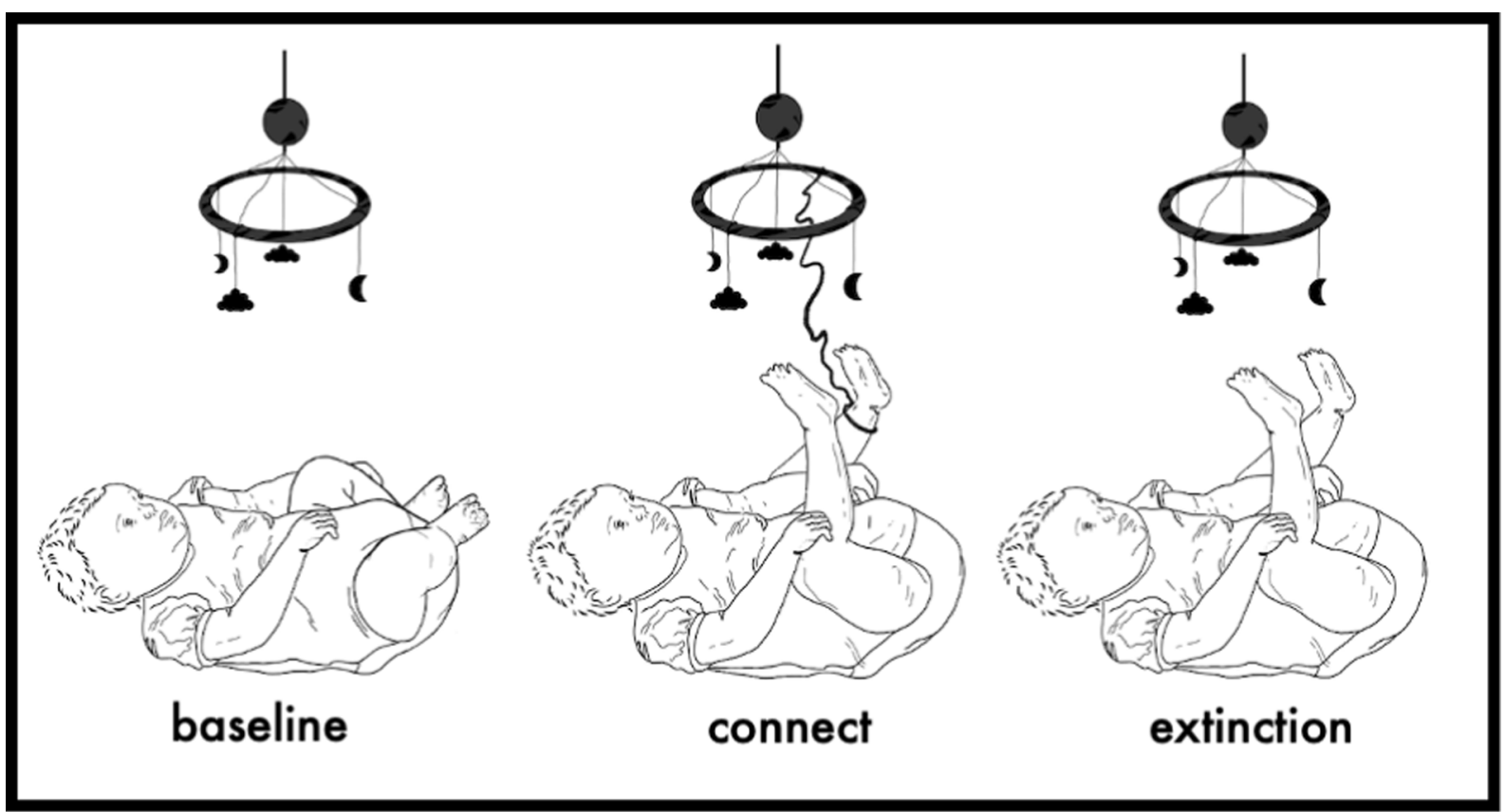

Fig. 2. Sketch of the three typical phases of the mobile paradigm as an example of an active contingency paradigm. In the baseline phase, infant's movements are measured without manipulation. In the connect phase, one limb is connected to the mobile via a ribbon and infant's movements are measured. Finally, a number of studies have included a disconnect phase in which infant's movement after disconnecting the limb from the mobile are measured. 
very similar videos, thus there is no factor making it necessary for the child to take specific actions. Infants passively observe a screen, display a visual preference, but it remains unclear to what extent they detect the self-relatedness of the visual input, their effect on the stimulus, nor whether they initiate and control their movements.

\section{Active contingency paradigms}

Another set of paradigms has overcome the problems of the purely observational setting of the passive contingency paradigms by allowing the infant to actively learn a contingency between its own motor responses (e.g., limb movements) and an external stimulus triggered by these movements (e.g., a mobile attached to the limbs). As these paradigms involve infants' active learning of a sensorymotor contingency rather than their passive visual preference for one stimulus over another, we refer to these paradigms as active contingency paradigms.

A paradigmatic example of an active contingency paradigm is the mobile paradigm (see Fig. 2). In this paradigm infants are placed in a crib equipped with an overhead mobile. After a first baseline phase where the infant passively observes the mobile, one of the infant's limbs is connected to the mobile causing it to move in reaction to movements of this limb (in the following referred to as the connect phase). It is then observed whether the infant increases the movement of the connected limb in the connect phase, triggering the rewarding mobile stimulus. Several different versions of this general paradigm exist with different triggering movements and different rewards. Another version, for example, linked a pressure sensor in a pacifier to a speaker, which either played a high or low pitch tone contingent with the sucking of the infant on the pacifier (Rochat \& Striano, 1999; see Table 2 for an overview of different active contingency paradigms).

More recently, Zaadnoordijk and her colleagues combined the mobile paradigm with an electroencephalography (EEG) measurement. This was achieved by using a video display and motion trackers instead of an actual mobile and a ribbon. Once the infant's limb movement exceeded a predefined threshold the video stimuli started to jiggle. The study found a mismatch negativity in the EEG signal corresponding to the disconnect phase, indicating a violation of expectation effect for those infants who also showed an extinction burst effect. The approach to combine contingency paradigms with imaging techniques is promising because it can be applied with infants in spite of their limited motor capacities. Along similar lines, Meyer and Hunnius (2021) published a study on infants' ability to differentiate self- from externally- produced events, including an EEG measurement. However, violation of expectation effects do not indicate agentic control. A violation of expectation neural indicator can be found with paradigms merely requiring a participant to observe a scene without doing anything. Thus, an identifiable signature for agency, agentic control or action has not been proposed, yet.

What these experimental set-ups have in common is that the effect of the infant's movement is manipulated such that the infant's movements and the reward are contingent in the connect phase, but non-contingent in the baseline phase. The theoretical assumption is that if the movement in the connect phase differs significantly from the movement in the non-connect baseline, infants are able to detect the contingent relation between, for instance, kicking with a leg and something happening.

Indeed, from the first introduction of this paradigm by Rovee and Rovee (1969) throughout many later versions of the experiment (see Table 2), it has been observed that infants do increase the frequency of the connected limb movement steadily throughout the connect phase in reaction to the contingent mobile response.

Following the theoretical tradition of Russell (1995), Piaget (1950) and Gibson (1988), these findings have been interpreted as showing infants' registration of the effect their own limb movement has on the mobile. Their increased limb movement has been assumed to show that they actively initiate more movement of this limb to drive the rewarding effect (Rochat \& Striano, 2000).

It has been pointed out, however, that a steady increase of the triggering movement would also occur in the same way through reinforcement learning without the need for infants to understand the causal relation between their movements and the rewarding stimulus (Kelso, 2016; Zaadnoordijk et al., 2018 \& 2019). Infants neither need to understand the causal relation, nor that they are the ones causing the rewarding effect and can control it. As reinforcement is anything that strengthens or increases the frequency of behavior while an extinction is the ceasing or fading out of the reinforced behavior, results from active contingency paradigms can therefore be perfectly explained in terms of classic conditioning models. Indeed, as Zaadnoordjik (2018) demonstrated by means of a computer simulation, the movement data collected during the connect phase perfectly matches responses from classical conditioning experiments (Rescorla, 1988).

In response, researchers have argued that the specificity of the effect indicates infants' registration of their own efficacy. According to Kelso (2016), it is not only the overall response measure that is informative about infants' agency, but coordinated movement interactions need to be considered as well. In the case of the mobile paradigm this means analyzing whether the contingency is driven by the infant, the pleasant stimulus or an interaction of both. Kelso and Fuchs (2016) present a theoretical model based on the movement of the infant, the motion of the mobile and the functional coupling between both. They conclude that, "a most remarkable aspect of MCR is that the baby — capable of producing spontaneous leg movements — rapidly realizes that it, not some outside force, is moving the mobile. A switching or kind of 'eureka effect' occurs between spontaneous and intentional movement. The faster the baby kicks, the more vigorously the mobile will move. This conjugate arrangement leads to a high and stable rate of leg movement, which subsides only when the ribbon is detached" (Kelso \& Fuchs, 2016, p. 50). According to Kelso (2016), such a coordinated interaction between the infant's leg movement and the motion of the mobile constitutes a meaningful interaction with the world, which indicates the infant's experience of themselves as an agent. Kelso and Fuchs (2016) argue that in the mobile paradigm, infant interaction with the mobile, which is driven by reinforcement learning, leads to a 'eureka effect' on the part of the infant about the role they themselves are playing in this interaction. The central assumption of their work is that conjugate reinforcement is brought about by an amplifying relation between the infant's movement and the motion of the mobile. A steady increase in kicking intensity results in an intensifying 
Table 2

Overview Active Contingency Paradigms.

\begin{tabular}{|c|c|c|c|c|c|c|c|c|}
\hline Authors & Year & $\begin{array}{l}\text { Description (EG - Experimental Group; CG - } \\
\text { Control Group) }\end{array}$ & Groups & $\begin{array}{l}\text { N Total } \\
\text { (N per } \\
\text { Group) }\end{array}$ & $\begin{array}{l}\text { Age (m - } \\
\text { month; h - } \\
\text { hours) }\end{array}$ & $\begin{array}{l}\text { Phases (B - Baseline; C - } \\
\text { Connect; D - Disconnect) }\end{array}$ & Main findings & $\begin{array}{l}\text { Effect Size/ } \\
\text { Cohen's d* }\end{array}$ \\
\hline Rovee \& Rovee & 1969 & $\begin{array}{l}\text { Mobile Paradigm in at Home testing session with } \\
\text { two independent observers. EG, one limb in } \\
\text { direct control of mobile motion. CG, } \\
\text { experimenter in direct control of mobile motion. }\end{array}$ & 2 & $\begin{array}{l}18(6 / \\
12)\end{array}$ & $3 \mathrm{~m}$ & $\begin{array}{l}\text { (EG) B, } 3 \mathrm{~min} / \mathrm{C}, 15 \mathrm{~min} / \\
\mathrm{D}, 5 \mathrm{~min} \\
\text { (CG) B, } 3 \mathrm{~min} / \mathrm{mC}, 15 \\
\mathrm{~min} / \mathrm{D}, 5 \mathrm{~min}(\mathrm{mC}-\mathrm{mock} \\
\text { connect) }\end{array}$ & $\begin{array}{l}\text { The experimental group increased kicking } \\
\text { significantly more than the control group in the } \\
\text { connect phase. Response levels in the } \\
\text { disconnect phase did not significantly differ } \\
\text { from baseline. }\end{array}$ & $\begin{array}{l}\text { ic }- \text { incalculable } \\
\text { with reported } \\
\text { data }\end{array}$ \\
\hline $\begin{array}{r}\text { Siqueland \& } \\
\text { Delucia }\end{array}$ & 1969 & $\begin{array}{l}\text { Pacifier Paradigm with visual stimuli contingent } \\
\text { to pressure and sucking frequency. Three groups: } \\
\text { (1) Baseline only; (2) Reinforcement; (3) } \\
\text { Stimulus Withdrawal. }\end{array}$ & 3 & $\begin{array}{l}30(10 / \\
10 / 10)\end{array}$ & $4 \mathrm{~m}$ & $\begin{array}{l}\text { (Group 1) B, } 10 \mathrm{~min} \\
\text { (Group 2) B ( } 2 \mathrm{~min}) ; \mathrm{C}(4 \\
\min ) ; \mathrm{D}(2 \mathrm{~min}) ; \mathrm{C}(4 \\
\mathrm{min}) ; \mathrm{D}(3 \mathrm{~min}) \\
\text { (Group 3) B, } 2 \mathrm{~min} / \mathrm{C}, 4 \\
\mathrm{~min} / \mathrm{D}, 2 \mathrm{~min} / \mathrm{C}, 4 \mathrm{~min} / \\
\text { D, } 3 \mathrm{~min}\end{array}$ & $\begin{array}{l}\text { The reinforcement group increased high } \\
\text { amplitude sucking significantly more than the } \\
\text { baseline and stimulus withdrawal groups. }\end{array}$ & ic \\
\hline \multirow[t]{2}{*}{$\begin{array}{l}\text { Rovee-Collier } \\
\quad \text { et al. }\end{array}$} & 1978 & $\begin{array}{l}\text { Exp 1: Mobile Paradigm in lab sessions with EG } \\
\text { (right leg in direct control of mobile motion) and } \\
\text { CG (no limb in direct control of mobile motion) }\end{array}$ & 2 & $\begin{array}{l}15(10 / \\
5)\end{array}$ & $3 \mathrm{~m}$ & $\begin{array}{l}\text { (EG) B, } 3 \mathrm{~min} / \mathrm{C}, 15 \mathrm{~min} / \\
\mathrm{D}, 5 \mathrm{~min} / \mathrm{C}, 10 \mathrm{~min} / \mathrm{D}, 5 \\
\mathrm{~min} \\
(\mathrm{CG}) \mathrm{B}, 3 \mathrm{~min} / \mathrm{mC}, 15 \\
\mathrm{~min} / \mathrm{D}, 5 \mathrm{~min} / \mathrm{mC}, 10 \\
\mathrm{~min} / \mathrm{D}, 5 \mathrm{~min}(\mathrm{mC}-\mathrm{mock} \\
\text { connect) }\end{array}$ & $\begin{array}{l}\text { The experimental group increased overall } \\
\text { average kicking of both legs more than the } \\
\text { control group. Only in D kicking of the } \\
\text { connected limb increased significantly more } \\
\text { than kicking of the unconnected limb. }\end{array}$ & ic \\
\hline & & $\begin{array}{l}\text { Exp 2: Mobile Paradigm in at home testing } \\
\text { session over } 4 \text { days. Reversal reinforcement } \\
\text { training, when infants kicking of the connected } \\
\text { limb was twice as much as of the unconnected } \\
\text { limb, connection was switched to unconnected } \\
\text { limb. }\end{array}$ & 2 & $13(4 / 9)$ & $3 \mathrm{~m}$ & $\begin{array}{l}\text { (Day 1) B, } 3 \min / C, 9 \\
\min / \mathrm{D}, 3 \mathrm{~min} \\
(\text { Day } 2-4) \mathrm{C}, 9 \mathrm{~min} / \mathrm{D}, 3 \\
\min \end{array}$ & $\begin{array}{l}\text { The overall kicking rate of the initially } \\
\text { unconnected limb was significantly higher than } \\
\text { the overall kicking rate of the initially } \\
\text { connected limb. However, only } 4 \text { infants } \\
\text { reached the threshold for the reversal } \\
\text { reinforcement training. }\end{array}$ & ic \\
\hline \multirow[t]{3}{*}{$\begin{array}{l}\text { Rovee-Collier } \\
\quad \text { et al. }\end{array}$} & 1980 & $\begin{array}{l}\text { Exp 1: Mobile Paradigm in at home testing } \\
\text { session two training sessions and reactivation } \\
\text { session either two or four weeks later with } \\
\text { reactivation stimulus (mobile moved by } \\
\text { experimenter without limb connection) } 24 \mathrm{~h} \\
\text { before the retention session. }\end{array}$ & 1 & 18 & $3 \mathrm{~m}$ & $\begin{array}{l}\text { (Training 1) B, } 3 \mathrm{~min} / \mathrm{C} \text {, } \\
9 \mathrm{~min} / \mathrm{D}, 3 \mathrm{~min} \\
\text { (Training } 2 \text { and } \\
\text { Retention) C, } 9 \mathrm{~min} / \mathrm{D}, 3 \\
\text { min }\end{array}$ & $\begin{array}{l}\text { The experimental groups in all three } \\
\text { experiments increased overall kicking responses } \\
\text { significantly more than the control group in the } \\
\text { retention session. }\end{array}$ & ic \\
\hline & & $\begin{array}{l}\text { Exp 2: Retention session } 4 \text { weeks after Training } 2 \\
\text { session. }\end{array}$ & 1 & 18 & $3 \mathrm{~m}$ & - & & \\
\hline & & $\begin{array}{l}\text { Exp 3: Retention session } 3,6,9 \text { or } 15 \text { days after } \\
\text { Training } 2 \text { session for } 5 \text { infants each time frame. }\end{array}$ & 1 & 20 & $3 \mathrm{~m}$ & - & & \\
\hline $\begin{array}{l}\text { DeCasper \& } \\
\quad \text { Carstens }\end{array}$ & 1981 & $\begin{array}{l}\text { Pacifier Paradigm with auditory stimuli } \\
\text { contingent to sucking frequency. Two groups: (1) } \\
\text { first session contingent, (2) second session non- } \\
\text { contingent }\end{array}$ & 2 & $8(4 / 4)$ & $53 \mathrm{~h}$ & $\begin{array}{l}\text { (Group 1) B, } 7 \mathrm{~min} / \mathrm{C}, 15 \\
\min / \mathrm{D}, 15 \mathrm{~min} \\
\text { (Group 2) B, } 7 \mathrm{~min} / \mathrm{D}, 15 \\
\min / \mathrm{C}, 15 \mathrm{~min}\end{array}$ & $\begin{array}{l}\text { Infants of group (1) did increase sucking during } \\
\text { (C) significantly more than infants of group (2). } \\
\text { Newborns learning is driven by perceptual } \\
\text { contingencies. }\end{array}$ & ic \\
\hline Lewis et al. & 1990 & $\begin{array}{l}\text { (Modified) Mobile Paradigm with an audio- } \\
\text { visual stimulus contingent on arm movement. By } \\
\text { pulling a string attached to their wrist } \\
\text { participants in EG could activate a } 3 \mathrm{~s} \\
\text { presentation of a smiling infant face and a }\end{array}$ & 8 & $\begin{array}{l}80(20 / \\
20 / 20 / \\
20)\end{array}$ & $2,4,6,8 \mathrm{~m}$ & $\begin{array}{l}\mathrm{B}, 2 \mathrm{~min} / \mathrm{C}, 3 \mathrm{~min} / \mathrm{D}, 2 \\
\mathrm{~min} / \mathrm{C}, 3 \mathrm{~min}\end{array}$ & $\begin{array}{l}\text { Infants in EG produced significantly more arm } \\
\text { pulling responses than infants in CG. Arm } \\
\text { pulling of the connected arm significantly } \\
\text { exceeded arm pulling of the unconnected arm } \\
\text { during C and D phases. }\end{array}$ & 1.022 \\
\hline
\end{tabular}

$\mathrm{min} / \mathrm{C}, 15 \mathrm{~min}$

$80(20 /$
$20 / 20 /$

$$
\text { 20) }
$$


Table 2 (continued)

\begin{tabular}{|c|c|c|c|c|c|c|c|c|}
\hline Authors & Year & $\begin{array}{l}\text { Description (EG - Experimental Group; CG - } \\
\text { Control Group) }\end{array}$ & Groups & $\begin{array}{l}\text { N Total } \\
\text { (N per } \\
\text { Group) }\end{array}$ & $\begin{array}{l}\text { Age (m - } \\
\text { month; h - } \\
\text { hours) }\end{array}$ & $\begin{array}{l}\text { Phases (B - Baseline; C - } \\
\text { Connect; D - Disconnect) }\end{array}$ & Main findings & $\begin{array}{l}\text { Effect Size/ } \\
\text { Cohen's d* }\end{array}$ \\
\hline & & $\begin{array}{l}\text { equally distributed amount of audio-visual } \\
\text { stimulus presentation. }\end{array}$ & & & & & & \\
\hline $\begin{array}{l}\text { Rochat \& } \\
\quad \text { Striano }\end{array}$ & 1999 & $\begin{array}{l}\text { Pacifier Paradigm with auditory stimuli } \\
\text { contingent to sucking pressure. In the analog } \\
\text { condition }(\mathrm{aC}) \text { the pitch of the auditory stimulus } \\
\text { was directly contingent to the pressure applied } \\
\text { by the infant. In the non-analog condition (naC), } \\
\text { the auditory stimulus was contingent to the } \\
\text { pressure applied by the infant, but the pitch of } \\
\text { the auditory stimulus was random. }\end{array}$ & 4 & $\begin{array}{l}32(14 / \\
18)\end{array}$ & $25,6 \mathrm{~h} / 2 \mathrm{~m}$ & $\begin{array}{l}\mathrm{B}, 90 \mathrm{~s} / \mathrm{aC}, 2 \times 90 \mathrm{~s} \text { and } \\
\text { naC } 2 \times 90 \mathrm{~s} \\
\text { (randomized)/B, } 90 \mathrm{~s}\end{array}$ & $\begin{array}{l}\text { Newborns and 2-months-olds did not show any } \\
\text { significant difference in response to both } \\
\text { experimental conditions. }\end{array}$ & $\begin{array}{l}\text { No significant } \\
\text { effect. }\end{array}$ \\
\hline Heathcock et al. & 2004 & $\begin{array}{l}\text { Mobile Paradigm in at home testing session } \\
\text { investigating difference between infants born } \\
\text { preterm and full-term. Three groups: (1) preterm } \\
\text { and (2) full-term experimental group and (3) one } \\
\text { full-term control group. For the control group an } \\
\text { experimenter controlled the mobile motion } \\
\text { during the connect phase. Longitudinal design, } \\
\text { infants were tested again either two weeks after } \\
\text { the first session (full-term and control group) or } \\
\text { each week for } 6 \text { consecutive weeks (preterm } \\
\text { group). }\end{array}$ & 3 & $\begin{array}{l}30(10 / \\
10 / 10)\end{array}$ & $3-4 \mathrm{~m}$ & $\begin{array}{l}\text { B, } 3 \min / C, 6 \min / \mathrm{D}, 3 \\
\min \end{array}$ & $\begin{array}{l}\text { The full-term group significantly increased } \\
\text { kicking in the connect compared to the baseline } \\
\text { phase, but the preterm group did not }\end{array}$ & $\begin{array}{l}\text { (1) No significant } \\
\text { effect./(2) } 0.286 / \\
\text { (3) } 0.217\end{array}$ \\
\hline $\begin{array}{l}\text { Watanabe \& } \\
\text { Taga }\end{array}$ & 2006 & $\begin{array}{l}\text { Mobile Paradigm with three age groups and } \\
\text { mobile motion contingent to either left or right } \\
\text { arm. }\end{array}$ & 3 & $\begin{array}{l}48(16 / \\
16 / 16)\end{array}$ & $\begin{array}{l}(2 \mathrm{~m} / 3 \mathrm{~m} / \\
4 \mathrm{~m})\end{array}$ & $\begin{array}{l}\mathrm{B}, 2 \mathrm{~min} / \mathrm{C}, 6 \mathrm{~min} / \mathrm{D}, 2 \\
\mathrm{~min} / \mathrm{C}, 2 \mathrm{~min} / 5 \mathrm{~min} \\
\mathrm{Break} / \mathrm{D}, 2 \mathrm{~min}\end{array}$ & $\begin{array}{l}\text { In each age group infants significantly increased } \\
\text { overall movement responses in the connect } \\
\text { compared to the baseline phase. But, only the } 4- \\
\text { months-olds specifically increased the } \\
\text { movement of the connected arm. }\end{array}$ & $\begin{array}{l}(2 \mathrm{~m}) \eta \mathrm{p}^{2}=0.183 \\
(3 \mathrm{~m}) \eta \mathrm{p}^{2}=0.282 \\
(4 \mathrm{~m}) \eta \mathrm{p}^{2}=0.238\end{array}$ \\
\hline \multirow[t]{2}{*}{$\begin{array}{l}\text { Watanabe \& } \\
\quad \text { Taga }\end{array}$} & 2011 & $\begin{array}{l}\text { Exp 1: Mobile Paradigm with arm, leg and low- } \\
\text { state, high-state groups. In experiment (1) } \\
\text { infants' wrists were connected to the mobile. } \\
\text { Dependent on their activity in the baseline phase } \\
\text { infants were post-hoc divided in low-state (less } \\
\text { than } 70 \mathrm{~mm} / \mathrm{s} \text { movement) and high-state groups } \\
\text { (more than } 70 \mathrm{~mm} / \mathrm{s} \text { movement). }\end{array}$ & 2 & $\begin{array}{l}111(54 / \\
57)\end{array}$ & $3 \mathrm{~m}$ & B, $2 \mathrm{~min} / \mathrm{C}, 4 \mathrm{~min}$ & $\begin{array}{l}\text { Infants in the low-state groups increased } \\
\text { movement responses in the connect phase } \\
\text { compared to the baseline phase, but infants in } \\
\text { the high-state groups did not. }\end{array}$ & $\begin{array}{l}\text { (1) } 1.137 \text { (low- } \\
\text { state) } \\
\text { (2) } 1.179 \text { (low- } \\
\text { state) }\end{array}$ \\
\hline & & $\begin{array}{l}\text { Exp 2: Infants' ankles were connected to the } \\
\text { mobile. }\end{array}$ & 2 & $\begin{array}{l}76(37 / \\
39)\end{array}$ & $3 \mathrm{~m}$ & B, $2 \mathrm{~min} / \mathrm{C}, 4 \mathrm{~min}$ & & \\
\hline $\begin{array}{l}\text { Zaadnoordijk \& } \\
\text { Hunnius } \\
\text { et al. }\end{array}$ & 2018 & $\begin{array}{l}\text { Simulation of Mobile Paradigm with MatLab } \\
\text { Baby Bot algorithm. }\end{array}$ & $\mathrm{n} / \mathrm{a}$ & $\mathrm{n} / \mathrm{a}$ & $\mathrm{n} / \mathrm{a}$ & $\mathrm{B} / \mathrm{C} / \mathrm{D}$ & $\begin{array}{l}\text { The Baby Bot reproduced the same effect } \\
\text { (increase of movement) observed in the connect } \\
\text { phase of a mobile paradigm. }\end{array}$ & $\mathrm{n} / \mathrm{a}$ \\
\hline $\begin{array}{l}\text { Zaadnoordijk \& } \\
\text { Hunnius } \\
\text { et al. }\end{array}$ & 2020 & $\begin{array}{l}\text { Mobile Paradigm with EEG Measure (Mismatch } \\
\text { Negativity). Audio-visual stimulus (digital) } \\
\text { contingent to arm movement of participant via } \\
\text { motion detector. }\end{array}$ & 1 & 36 & $\begin{array}{l}3-4.5 \\
\text { months }\end{array}$ & $\begin{array}{l}\text { B, } 2 \min / C, 3.5 \min / \mathrm{D}, 2 \\
\min \end{array}$ & $\begin{array}{l}\text { Only } 10 \text { infants showed a mismatch negativity } \\
\text { effect in response to D compared to C. }\end{array}$ & ic \\
\hline
\end{tabular}

All effect sizes calculated according to Lakens (2013). 
Table 3

Effect Sizes for Extinction Burst.

\begin{tabular}{|c|c|c|c|c|c|c|c|}
\hline \multirow[t]{2}{*}{ Authors } & \multirow[t]{2}{*}{ Year } & \multicolumn{6}{|c|}{ Results movement frequency } \\
\hline & & Mean Connect & Mean Disconnect & SD Connect & SD Disconnect & $\mathrm{N}$ & Effect Size/Cohen's d \\
\hline Rovee \& Collier & 1978 & not reported & - & - & - & 15 & ic - incalculable \\
\hline Lewis et al. & 1990 & 6.07 & 9.37 & 3.8 & 5.48 & 48 & 0.70 \\
\hline Heathcock & 2004 & 8.0 & 10.9 & 6.9 & 9.4 & 10 & 0.35 \\
\hline Zaadnoordijk et al. (overall)* & 2020 & 0.5459 & 0.9408 & 1.059 & 1.593 & 36 & 0.29 \\
\hline Zaadnoordijk et al. (connected)* & 2020 & 0.6257 & 1.1376 & 1.089 & 1.577 & 36 & 0.38 \\
\hline
\end{tabular}

" Data kindly provided by the author.

mobile motion, while an intensifying mobile motion results in an increase in kicking intensity. With the help of their model they show that this amplifying relation increases kicking and mobile motion until a stable threshold level is reached. At this point, Kelso and Fuchs argue, the infants realize that more intense kicking will not yield a more pleasant reward and therefore they have understood their own efficacy in the mobile paradigm.

However, a methodological weakness of this study is that the motion of the mobile has never actually been captured in mobile paradigm studies. Kelso and Fuchs base their model purely on verbal reports by other researchers (Kelso \& Fuchs, 2016, p. 44).

Moreover, and more importantly, although the criticism regarding Rochat and Striano's (2000) view on early agency and active contingency paradigms by Kelso and Fuchs is well placed, their interpretation neglects that the effect found in the connect phase matches the results of conditioning experiments (Zaadnoordijk et al., 2018). Classical conditioning also predicts an increase of the movement until the triggering threshold is reached. It thus remains unclear to what extent infants realize the effect of their own kicking and can control it, or whether their behavior reflects reinforced movement out of the infants' control.

Further substantial criticism is presented by Zaadnoordijk et al. (2019), who make a strong argument against these findings being sufficient for demonstrating a sense of agency. They argue that it needs more than a simple mechanism detecting match or mismatch in predicted and observed sensory consequences, even if these result in coordinated movement interactions. What is required instead is the ability to draw a causal inference about the history of the detected match or mismatch. "Namely, the sense of agency requires an internal representation of an action by the agent (an ownership predicate), a perceived event and an inferred causal relation between the two. Additionally, to account for the corresponding feeling, a phenomenological dimension is required" (Zaadnoordijk et al., 2019, p. 4). In this view, for infants to possess a sense of agency they have to be able to register their own bodily movements, the consequences of those movements and they have to be able to link cause and effect in the perceived event.

To address this criticism, Zaadnoordijk et al. suggest focusing on a third phase that some mobile paradigm studies include. After the connect phase these studies disconnected the infant's limb from the mobile and observed the infant's response to the absence of an effect upon their limb movement.

It was observed in a few studies that in this disconnect phase, the leg movement increased rapidly and then dropped to the frequency level observed in the baseline condition (Lewis et al., 1990; Heathcock et al., 2004; Rovee-Collier et al., 1978; Zaadnoordijk et al., 2018, 2020), an effect that has been referred to as the extinction burst. This effect has only been observed in a handful of studies (see Table 3) and has only recently been investigated more systematically (Zaadnoordijk et al., 2018, 2020) (see Table 3). Immediately after being freed from the connection to the mobile, infants' overall limb movement increases abruptly. Table 3 shows the average movement data of the connect and disconnect phase for the few studies that reported an extinction burst. For Zaadnoordijk et al, (2020) and Heathcock et al. (2004), a small to medium effect was observed, while Lewis et al. (1990) reported a medium to large effect. Only one study tested whether the observed extinction burst was specific to the attached limb and did not find a significant difference between movement of all limbs and movement of the connected limb in the disconnect phase at the group level. Zaadnoordijk and colleagues did however observe a limb specific extinction burst for the ten infants also showing a mismatch negativity effect (Zaadnoordijk et al., 2020).

In contrast to the increasing limb frequency throughout the connect phase, the extinction burst effect cannot be explained by pure reinforcement learning, as this would predict an extinction of the effect (Zaadnoordijk et al., 2018). It has therefore been argued that it indicates more than just a reinforced stimulus-response pattern. Lewis et al. (1990), for example, interpreted this rapid increase of limb movement directly after being disconnected from the mobile as frustration over a loss of control, suggesting that infants had felt in control and understood the effect their movement had on the mobile. They compared 2-8 months-old infants' facial expressions in an active contingency paradigm (Lewis et al., 1990) with a control group that received comparable audiovisual stimulation but without contingency to their leg motion. Interestingly, infants in the control group did not increase leg motion. Lewis et al. also analyzed infant's facial/emotional expressions and found that, irrespectively of the experimental condition, infants from 4 months of age displayed expressions of anger. Because only infants that had the opportunity to control the contingency showed increased leg motion, the authors argued that their findings indicate that infants were frustrated about a loss of control. However, the results do not unambiguously indicate what the infants were frustrated about. It could be the loss of control but it could also be the extinction of the experience of a pleasant contingency between leg motion and stimulus presentation.

Likewise, Zaadnoordijk et al. (2019) argued that the extinction burst results from infants probing the causal relation between their limb movement and its effect on the mobile after the failure of this effect, or, similarly, that the extinction burst reflects a violation of expectation after infants had learned the causal relation between their action and its effect on the mobile (Zaadnoordijk et al., 2020). "This was why, in contrast to previous research, our focus was on the violation of expectation, as this indicates that infants have made a 
prediction regarding the consequences of their action and thus have built an internal model" (Zaadnoordijk et al., 2020, p. 17). These interpretations of the extinction burst suggest that it shows infants' realization of the effect their own limb movement has on the mobile followed by a realization of failure of their efficacy.

However, an alternative explanation for infants' increased movement might be their frustration over the sudden lack of a previously experienced contingency (i.e., mobile movement when limb movement). This interpretation does not require any realization on the part of the infants that their movements caused the effect. Instead, they might have shown an automated response reinforced by the positive reward of the mobile movement in the connect phase, and then show an emotional response (e.g., frustration or distress) due to the missing visual reward during the disconnect phase. This alternative explanation appears particularly plausible given the lack of evidence for the specificity of this effect to the connected limb. Infants appear to show an overall increase of their limb movements, rather than specifically probing the causality between the movement of the attached limb and the mobile.

In sum, flexibility and specificity of extinction burst effects have not yet been robustly shown. The effect does not appear to be specific to the previously connected limb (see Table 3), nor have signs of a controlled or targeted movement been reported that would be adapted to the specific situation. Moreover, the movement is of the same kind as in the connect phase and therefore does not display any flexibility on the part of the infant. It might present an increase of the reinforced movement out of a general frustration resulting from the lack of contingency. In contrast, if the infant was in possession of agentic control over its bodily movements, the reaction to the missing effect related to its cause should be a specific and controlled movement.

It is worthwhile to point out that Rovee-Collier intended the mobile paradigm as an experiment to investigate infants' learning and memory capacities. Over the years some adaptations of the original design focused more on differences in infants' motor responses. One adaptation of the active contingency testing procedure worth to be considered in this discussion was introduced by Rovee-Collier in 1987..$^{6}$ This adaptation included a further step in the procedure: after participating infants had reach a certain kicking-threshold (pre-determined amount of leg movement) with one leg in the connect phase, the connection was switched to the other leg. The results show that the overall kicking rate of the initially unconnected limb was significantly higher than the overall kicking rate of the initially connected limb. Although only four of 13 infants reached the threshold for the reversal reinforcement training it is intriguing to think that infants seem to be able to transfer the learned contingency rapidly from one leg to the other. A further experiment worth mentioning was reported by Watanabe and Taga (2006), where 2 and 4 months-old infants were tested in the standard active contingency design. Results showed that only the 4 months-old infants increased movement specifically of the connected arm, while 2 months-olds showed increased overall limb movement. This indicates that instrumental learning may develop from general to specific in the first 6 months of infants' lifes. However, Jacquey et al., (2020) failed to replicate the findings by Watanabe and Taga (2006). In sum, more variations of the standard active contingency design are needed that investigate the variability of infants' responses and their ability to transfer the learned contingency to new situations. Of special interest are infant's specific movement responses, for example increased movement only of the connected limb in both connect and disconnect phases. Such flexibility in infants' response may show flexible adaptation to new circumstances and will thus give a better understanding of how the ability to control movement develops.

Taken together, active contingency paradigms report two interesting effects. The first effect is observed during the connect phase, when a contingent relation between movement and reward is established. During this phase infants increase the frequency of the rewarded movement in response to the contingency. This effect is very robust and has been found throughout studies with active contingency. As argued above, however, this effect is perfectly predicted by automatic reinforced response patterns that do not require infants to understand that their movements cause the rewarding effect, nor that they actively initiate and control these movements. The second, more interesting, effect found in only a few studies in relation to infant agency is the extinction burst observed shortly after the mobile has been disconnected. This effect cannot be explained by mere reinforcement learning and has been interpreted as showing that infants understood that their actions caused an effect during the connect phase and were now surprised or frustrated about the failure of this effect. However, we have argued that the increased movement of the child might also express their frustration over the lack of a contingency (the mobile movement) that they got used to before. This explanation of the effect does not require the child to be an agent in the situation. Instead, infants' increasing limb movement in the connect phase might result from reinforcement learning, and the subsequent extinction burst might reflect a general frustration over the sudden absence of a previously experienced contingency.

Experiments with control groups (e.g., Lewis et al., 1990) report that only infants that had the opportunity to control the contingency show an extinction burst. However, infants in the control groups displayed expressions of anger as did infants in the experimental groups. Thus, these findings cannot conclusively rule out our alternative interpretation because it cannot be retrospectively determined what elicited the expression of anger. Thus, none of these effects require the infant to understand the relation between their own limb movements and the visual reward. Moreover, none of the effects require the infant to control their movements. Rather, they might reflect mere automated conditioned or emotional responses. What would be required for these movement responses to show infants' minimal agency would be a sign of the infants' flexible and adapted agentic control over their bodily movements, especially in the situation of changing circumstances (e.g., the sudden breakdown of the contingency).

One sign of agentic control in this sense could be more specific movements of the previously connected limb after the disconnection of the mobile that more clearly indicated a probing of a previously learned contingency. Such a specific and controlled response to a changed circumstance, rather than a more general increase of movement that might indicate general frustration, might be a first

\footnotetext{
${ }^{6}$ We thank an anonymous reviewer for reminding us of this adaptation in the work of Rovee-Collier.
} 
indication of infants' flexible possession and exertion of agentic control over their bodily movements, thus qualifying them as controlled actions.

In conclusion, active contingency paradigms demonstrate infants' vastly expanding instrumental learning capacities. These capacities are most definitely part of infants' developmental pathway to agency. However, we have argued that those paradigms do not conclusively show that infants are in control over their movement because the experimental design does not allow for a convincing differentiation of reflexive, conditioned, emotional or controlled movement.

Before we turn to motor development research, we now introduce paradigms building on anticipation and evaluation of action outcomes.

\section{Paradigms on anticipation and evaluation of action outcomes}

In the previous paragraph, we discussed the interpretation of extinction burst findings in active contingency paradigms. We have argued that it is plausible but not warranted to assume infants' frustration response is elicited by a lack of control, because these paradigms do not specifically measure agentic control. However, anticipation and evaluation of action outcomes has been investigated by further paradigms as well.

For example, eye movements can be highly informative about expectation and anticipation of effects if experiments are designed well and suitable for the targeted age group. Velocity, fixation time and direction of gaze can be used to measure flexible adaptation to new circumstances. From about 3 months of age infants fixate and move their gaze in target-directed ways, making gaze tracking an interesting measure to assess eye movement control. Anticipatory gaze shifts, in particular, have been used to investigate whether infants anticipate, and thus represent, the outcome of their own actions (Kenward, 2010). To this end, Kenward (2010) trained 10months-old infants to press a large button which started a short funny video clip on a screen right in front of the infants. While the infants repeatedly pressed the button and watched the video their gaze was recorded with an eye-tracker. The gaze data revealed that infants gazed at the location where the stimulus would appear on the screen more often one second prior to the button press compared to the rest of the duration of the experiment, indicating their anticipation of the outcome of their button press action. These findings are interpreted as evidence for infants' ability to represent the outcome of their action. Indeed, the anticipation of the reward indicates that infants display a robust outcome expectation and that this expectation is coupled with a movement performed by the infants. However, Kenward points out that "infants would learn by reinforcement to shift gaze as a habitual response to the internal stimulus of the sensation of preparing to press the button, without expecting anything specific to occur at the gaze shift goal" (Kenward, 2010, p. 355356). This aspect also calls into question to what extent infants possess agentic control over the reinforced movement as infants might learn the contingency between the internal sensation of preparing a movement and the outcome without necessarily being in control over this movement. Similar research along these lines has been conducted with so called outcome revaluation paradigms. These paradigms manipulate the reward in response to a trained movement and evaluate the participants' likeliness to perform these movements depending on the expected reward value (Kenward et al., 2009; Klossek et al., 2008). ${ }^{7}$ Klossek et al. (2008) for example, trained infants to touch red and green butterfly icons on a screen by rewarding the touches with attractive videos. In a series of experiments where the reward for either of the two possible movements was manipulated they showed that infants over three years of age are able to evaluate the outcome of an action and adapted their response accordingly. These findings show that three year old infants account for reward values when producing movements. Younger infants in this study did not show a differentiated response to reward revaluation. The results of the younger age group (18- to 27-month-olds) are thus inconclusive as to whether the infants merely moved because of a reward or if they anticipated a reward and thus performed an action (cf. Klossek et al., 2008, p. 47-48). As such anticipation and evaluation of action outcome paradigms face similar shortcomings as active and passive contingency paradigms, for they do not specifically measure agentic control. Further, as infants participating in these paradigms where already 18 months old, we expect them, based on work by von Hofsten and others, to possess the ability to control bodily movements and anticipate the outcome of their actions. Thus, paradigms comparable to these outcome revaluation studies need to be adapted for younger children in order to better investigate the development of agency.

In the following, we will discuss paradigms that have studied motor development in infancy. So far, these have not been explicitly linked to minimal agency. However, we will argue that a combination of measures of more specific and flexible agentic control with classical contingency paradigms has the potential to increase our understanding of the specific developmental steps infants pass by on their way to becoming full-fledged agents.

\section{Paradigms on flexible action control}

Above we provided arguments as to why agentic control is a necessary criterion to distinguish actions from other bodily movements like reflexes, automated conditioned, or emotional bodily responses. Here, we highlight experimental paradigms that have been developed to test infants' motor control. We argue that using such measures of infants' motor control in the context of infants' reaction to changing multi-sensory contingency may open a new avenue to addressing the question of minimal agency more unambiguously.

A promising measure of controlled movements that might be used in agency tasks are measures of infants' controlled and flexible reaching or grasping. From about 8 months, infants reach for, and grasp objects efficiently that are placed within their surroundings

\footnotetext{
${ }^{7}$ We thank an anonymous reviewer for directing us to this work.
} 
(von Hofsten, 1991, 2004). Claes von Hofsten published several studies on the development of infants reaching and grasping. He showed that newborns forward directed arm movement is influenced by the visual fixation of a nearby object (1982). In a longitudinal study he analyzed the influence of bodily stability on infants' reaching movement (1991). His results showed that the structure and effectiveness of reaching movement is dependent on bodily stability. Infant reaching at 5 months is rather clumsy and unstructured while already at 8 months infants display efficient and structured reaching movements. Based on the work of von Hofsten several further experiments on infants' motor development have been conducted (for a review see. Adolph \& Berger, 2006).

Most recently, Gottwald (2018) developed a measure of infants' flexible control of their reaching and grasping movements based on von Hofsten's work. For this purpose, they measured peak velocity of movement onset in three different reach-to-place tasks with varying difficulty. Infants were repeatedly shown by their caregivers how to reach for an object and then place it in a cylindrical container. Caregivers then encouraged the infant to do the same. Throughout the experiment the difficulty level was changed by moving the cylinder farther away and switching it for a cylinder with a smaller diameter. Gottwald and colleagues found that 14month-olds adjusted the velocity of their reaching movement to the difficulty level of the task. They interpreted these findings as evidence for infants' ability to prospectively control their bodily movements.

We suggest that adaptation of movement velocity to a specific and changing target might also serve as an index of agentic control in the context of minimal agency tasks. The paradigm by Gottwald (2018) focused on motor control during the execution of reaching movements and did not target agency. The task on its own is not sufficient to show infants' minimal agency, as this would require evidence that their reaching indeed constitutes agentically controlled actions and does not result from an automatic motor program. Reaching for objects presents a natural and highly adaptive situation, for which a sophisticated motor program is likely to exist that would not require the ability to flexibly adapt one's actions. Already in 1979, von Hofsten described how reaching movements can be divided into units of acceleration and deceleration. This fundamental structure of human motor behavior has been shown in infants as well as in adults and this structure is unaffected by the level of skill (von Hofsten \& Lindhagen, 1979; Abend et al., 1982; Fetters \& Todd, 1987). To demonstrate that the observed reaching indeed presents an agentically controlled action, infants would need to demonstrate the ability to initiate and adapt these movements flexibly under novel and changing circumstances for which a motor program is unlikely to exist. Infants might, for example, be required to learn a novel contingency between their movements and an effect in the world and might then be asked to adapt their movements to a new situation in a controlled way. For example, an infant might learn the contingency between an arm movement and a mobile movement via the attached string. In the disconnect phase of the mobile paradigm an infant could display agentic control by grasping and pulling the disconnected string. Importantly, the introduced measure of motor control in grasping and reaching movements (Gottwald, 2018) might serve to measure infants' agentic control in such a changing situation, and therefore presents a highly promising measure to test for infants' minimal agency in the context of previously used contingency paradigms.

In addition to infants' grasping and reaching abilities, influences of posture, crawling and walking on infants' responsiveness to changing environmental affordances has been investigated intensively. For example, Soska and Adolph found that early object exploration is dependent on postural constraints (Soska \& Adolph, 2014). Further research in the area of motor development addresses the influence of walking on infant learning. Adolph et al. (1993) investigated differences between crawling and walking infants in their response to affordances. Berger et al. (2005) found that walking infants can adapt their movement to different circumstances (for a review see. Adolph et al., 2008). These extensive research programs show that infants' development of agentic control is dependent on their motor development. The more motoric abilities infants develop, the more proficient they become at controlling movement. Importantly, to investigate the onset of this development a modality with few motor and bodily constraints should be chosen, such as eye movement and vocalization.

However, in the next paragraph we propose to combine measures and ideas from both groups of paradigms to create a novel test for the development of minimal agency.

\section{A novel test for the development of minimal agency}

We build our proposal on a novel gaze contingent eye-tracking design. Instead of tracking flexible and controlled limb motion, eye tracking promises to be a fruitful measure to investigate the development of agency. To investigate whether infants intentionally control their eye movements, Miyazaki, Takahashi, and colleagues (2014) measured infants' gaze behavior when presented with gazecontingent stimuli. More specifically, by gazing at a black screen, 8-month-old infants as well as adults were able to scratch off the black layer with their gaze point under which a colorful picture appeared. After $130 \mathrm{~s}$, the gaze-contingent screen response stopped and participants were no longer able to reveal the image (interruption phase for ten seconds). With this paradigm, Miyazaki et al. found that adults, who later reported to have been aware of the gaze-contingency of the stimuli, showed more eye movements to the black screen areas in the gaze-contingent as well as the interruption phase. By comparing infants' gaze behavior to the adult gaze patterns, they then divided infants into active and passive viewers and interpreted similar levels of exploration in the active viewer infants as indication that the eye movements of these infants were driven by their motivation to explore the underlying image.

This experiment is promising for the investigation of the developmental transition from spontaneous to intentional behavior. Moreover, although the authors do not target the question of agency in infancy, we believe that with small adaptations this paradigm lends itself perfectly to addressing this question. The general framework of the paradigm with a contingency-learning phase followed by a phase in which this contingency breaks down is very similar to the classic active contingency paradigms, such as the mobile paradigm, also including a disconnect phase at the end. In addition, eye-tracking allows for very fine-grained movement tracking which could be implemented as a non-verbal measure of specific and flexible agentic control, in particular during the interruption phase of the experiment. The critical point would be to measure specific and targeted eye movements to those screen areas that have 
not been scratched off yet and promise novel visual input, particularly in the interruption phase.

Eye tracking is promising because gaze may be controlled more precisely and specifically earlier on in contrast to limb movement, which remains relatively unspecific for a long time after birth. Additionally, eye trackers offer a high-resolution measurement of behavior together with adjustable stimuli presentation. In contrast to the mobile paradigm, experimenters can precisely control the contingency reward, which offers further opportunities for manipulation in experimental designs. Thus, measuring flexible adaptation in gaze patterns to changing conditions in a previously learned environment opens a highly promising avenue to study minimal agency. Importantly, we do not argue that agentic control cannot be shown in limb movement. Rather, we merely propose another avenue for further research, which arguably has advantages over existing paradigms.

In conclusion, while the studies by Gottwald et al., Kenward and Miyazaki et al. offer promising approaches for the study of agency in infancy, neither have targeted agency yet. Combining these experimental paradigms with the setting of a contingency paradigm with phases of changing contingencies provides a novel and promising perspective for research on minimal agency.

\section{Discussion}

Previous studies have proposed that infants' ability to respond differently to contingent and non-contingent sensory stimulation reflects their ability to distinguish self-movement from other-movement, forming the basis for development of agency. Moreover, it has been argued that increased movement in response to a rewarding contingent stimulus (e.g., a moving mobile) or to the interruption of this contingency (referred to as extinction burst) show infants' ability to compute causal inferences about their own efficacy. We have argued that results of these studies are inconclusive as to whether infants indeed realize that these movements are their own and that they are the ones driving the contingency. Additionally, we argued that it is unclear whether these movements constitute actions at all or reflect mere movement.

On the one hand, findings from passive contingency paradigms remain uninformative about self-reference detection by the infant and thus do not support claims about the development of agency. On the other hand, increasing movement responses in the connect phase of active contingency paradigms can be explained as reinforced movements that may not require agentic control. Finally, the extinction burst effect, being unspecific and uncontrolled, might thus reflect an emotional response to the sudden absence of a learned contingency, and is therefore uninformative about infants' registration of their own efficacy. Nevertheless, the reciprocal sensorymotor learning capacities displayed by infants in active and passive contingency paradigms are necessary developmental steps in infants' process of becoming minimal agents. The sensory input gained through these reciprocal relations is, for example, important for the development of a body map and the computation of movements.

For results of a behavioral paradigm to be informative about minimal agency, this paradigm necessarily needs to include a measure of agentic control. More precisely, what is needed is a paradigm in which flexible control can be measured in a situation that does not allow for automated response patterns. For the critical measure, therefore, situations would need to be avoided where infants might show conditioned stimulus-response patterns (e.g., as in the connect phase of the mobile paradigm), where the infants' behavior is unspecific and might, for example, reflect an emotional response (e.g., the overall increased limb movement once the mobile is disconnected), as well as natural and highly adaptive situations for which a predisposed motor program might exist (e.g., grasping for objects). One way to avoid such situations might be by requiring infants to learn movements in a new environment with previously unknown effects, and then to adapt these movements in specific and controlled ways to a change in this learned environment. For this, a paradigm combining an actively learned contingency with a disruption phase while measuring agentic control seems promising. Specifically, infants could be confronted with an active contingency learning situation (e.g., gaze-contingent scratching) and this contingency could then be interrupted, while a controlled and specific response of the infant to this interruption (e.g., their eye movements) would need to be measured. The measurement of control over a specific targeted response in the disconnect phase would then be informative about infants' minimal agency. Hypotheses about outcome measurement would depend on the detail of the presented stimuli and involved sensory modalities (visual, proprioceptive, auditive or other) and motor aspects (e.g., limb, hand or eye movements). The essential part is to measure agentic control. Gottwald (2018) relied on movement onset velocity while Miyazaki et al. (2014) attempted to differentiate random gaze from directed gaze. Both approaches allow measurement of control but would need to be combined with learning situations to show the infants' ability to flexibly adapt controlled actions to a changing environment. Importantly, it does not suffice to show that movement changes between contingent and disrupted stimuli presentation, for only when movement changes in controlled and specific ways can we infer that infants possess minimal agency.

\section{Summary and conclusion}

We have argued that agentic control is an essential element of minimal agency and that without a measure of agentic control it is impossible to distinguish actions from other bodily movements. We have discussed active and passive contingency paradigms and their interpretation in the context of infant agency. We argue that neither class of paradigms shows convincingly that infants' take over control in these situations.

At the beginning of this review we set out to argue that to give an answer to the question how infants develop agency it is necessary to measure infants' ability to control their actions. We presented theoretical arguments as to why agentic control is the only aspect of behavior that allows to differentiate what an agent does from what merely happens to them in experimental paradigms. Our discussion of active and passive contingency paradigms and their interpretation shows that without a measure of infants' agentic control it remains ambiguous whether the infant's movements go beyond automated motor responses and thus indeed constitute actions.

Therefore, we have argued that a measure of agentic control needs to be included in any experimental paradigm aiming to show 
minimal agency in pre- or nonverbal populations. We have pointed to work on infants' motor development and flexible behavioral responses as a promising alternative. More specifically, we propose to combine contingency detection paradigms with paradigms targeting flexible behavioral responses, building on motor domains that are present from very early in life, such as eye movement. By confronting infants with changing circumstances while measuring their ability to take control over their bodily movements in specific reaction to the changed situation, we might be able to demonstrate infants' minimal agency from early on in life.

\section{Declaration of Competing Interest}

The authors declare that they have no known competing financial interests or personal relationships that could have appeared to influence the work reported in this paper.

\section{Acknowledgements}

We thank Elizabeth Kelly for proofreading the manuscript and Franziska Bednarski for drawing the illustrations. The authors would also like to thank all members of the Minerva Fast Track Research Group Milestones of Early Cognitive Development and the Cognitive Anthropology Research Group at the Leipzig Research Center for Early Child Development for many enlightening discussions.

\section{References}

Abend, W., Bizzi, E., \& Morasso, P. (1982). Human arm trajectory formation. Brain: A Journal of Neurology, 105(Pt 2), 331-348.

Adolph, K. E., Eppler, M. A., \& Gibson, E. J. (1993). Crawling versus walking infants' per- ception of affordances for locomotion over sloping surfaces. Child Development, 64(4), 1158-1174.

Adolph, K. E. \& Berger, S. E (2006). Motor development. In W. Damon \& R. Lerner (Series Eds.) \& D. Kuhn \& R. S. Siegler (Vol. Eds.), Handbook of child psychology. Cognition, perception, and language (Vol. 2, 6th ed., pp. 161-213). New York: Wiley.

Adolph, K., Joh, A. S., Franchak, J. M., Ishak, S., \& Gill-Alvarez, S. V. (2008). Flexibility in the development action. In The psychology of action (pp. 399-426). Oxford University Press.

Bahrick, L. E., \& Watson, J. S. (1985). Detection of intermodal proprioceptive-visual contingency as a potential basis of self-perception in infancy. Developmental Psychology, 21(6), 963-973.

Bayne, T., \& Pacherie, E. (2007). Narrators and comparators: The architecture of agentive self- awareness. Synthese, $159(3), 475-491$.

Begum Ali, J., Thomas, R. L., Mullen Raymond, S., \& Bremner, A. J. (2021). Sensitivity to Visual-Tactile Colocation on the Body Prior to Skilled Reaching in Early Infancy. Child Development, 92(1), 21-34.

Berger, S. E., Adolph, K. E., \& Lobo, S. A. (2005). Out of the toolbox: Toddlers differentiate wobbly and wooden handrails. Child Development, 76(6), $1294-1307$. Blakemore, S. J., \& Frith, C. (2003). Self-awareness and action. Current Opinion in Neurobiology, 13(2), $219-224$.

Braun, N., Debener, S., Spychala, N., Bongartz, E., Sörös, P., Müller, H. H., \& Philipsen, A. (2018). The senses of agency and ownership: A review. Frontiers in Psychology, 9, 535.

Bremner, A. J., Holmes, N. P., \& Spence, C. (2008). Infants lost in (peripersonal) space? Trends in Cognitive Sciences, 12(8), 298-305.

Bremner, A. J., Lewkowicz, D. J., \& Spence, C. (Eds.). (2012). Multisensory development. Oxford University Press.

Bremner, A. J. (2017). The origins of body representations in early life. In F. D. Vignemont, \& A. J. T. Alsmith (Eds.), The Subject Matter. Self-Consciousness and the Body (pp. 3-31). MIT Press.

Buehler, D. (2019). Flexible occurrent control. Philosophical Studies, 176(8), 2119-2137.

Craig, C. M., \& Lee, D. N. (1999). Neonatal control of nutritive sucking pressure: Evidence for an intrinsic $\tau$-guide. Experimental Brain Research, 124(3), 371-382. DeCasper, A. J., \& Carstens, A. A. (1981). Contingencies of stimulation: Effects on learning and emotion in neonates. Infant Behavior and Development, 4, 19-35.

Fetters, L., \& Todd, J. (1987). Quantitative assessment of infant reaching movements. Journal of Motor Behavior, 19(2), 147-166.

Filippetti, M. L., Johnson, M. H., Lloyd-Fox, S., Dragovic, D., \& Farroni, T. (2013). Body perception in newborns. Current Biology, $23(23)$, 2413-2416.

Filippetti, M. L., Orioli, G., Johnson, M. H., \& Farroni, T. (2015). Newborn body perception: Sensitivity to spatial congruency. Infancy, $20(4), 455-465$.

Filippetti, M. L., Farroni, T., \& Johnson, M. H. (2016). Five-Month-old Infants' Discrimination of Visual-Tactile Synchronous Facial Stimulation. Infant and Child Development, 25(3), 317-322.

Frankfurt, H. G. (1978). The problem of action. American Philosophical Quarterly, 15(2), 157-162.

Fridland, E. (2014). They've lost control: Reflections on skill. Synthese, 191(12), 2729-2750.

Fridland, E. (2017). Skill and motor control: Intelligence all the way down. Philosophical Studies, 174(6), 1539-1560.

Gergely, G., \& Watson, J. S. (1999). Early socio-emotional development: Contingency perception and the social-biofeedback model. Early Social Cognition: Understanding others in the First Months of Life, 60, 101-136.

Gibson, E. J. (1988). Exploratory behavior in the development of perceiving, acting, and the acquiring of knowledge. Annual Review of Psychology, 39(1), 1-42.

Gibson, E. J., \& Adolph, K. E. (1992). The perceived self in infancy. Psychological Inquiry, 3(2), 119-121.

Gibson, E. J. (1994). Has psychology a future? Psychological Science, 5(2), 69-76.

Gottwald, J. M. (2018). Measuring prospective motor control in action development. Journal of Motor Learning and Development, 6(s1), s126-s137.

Hadders-Algra, M. (2010). Variation and variability: Key words in human motor development. Physical Therapy, 90(12), $1823-1837$.

Heathcock, J. C., Bhat, A. N., Lobo, M. A., \& Galloway, J. (2004). The performance of infants born preterm and full-term in the mobile paradigm: Learning and memory. Physical Therapy, 84(9), 808-821.

Hiraki, K. (2006). Detecting contingency: A key to understanding development of self and social cognition. Japanese Psychological Research, 48(3), 204-212.

Hommel, B. (2015). Action Control and the Sense of Agency. In P. Haggard, \& B. Eitam (Eds.), The Sense of Agency (pp. 307-326). OUP.

Hyman, J. (2015). Action, knowledge, and will. OUP.

Jacquey, L., Fagard, J., Esseily, R., \& O'Regan, J. K. (2020). Detection of sensorimotor contingencies in infants before the age of 1 year: A comprehensive review. Developmental Psychology, 56(7), 1233.

Jacquey, Popescu, Vergne, Fagard, Esseily, O'Regan, et al. (2020). Development of body knowledge as measured by arm differentiation in infants: From global to local? British Journal of Developmental Psychology, 38(1), 108-124. https://doi.org/10.1111/bjdp.12309

Kelso, J. S. (2016). On the self-organizing origins of agency. Trends in Cognitive Sciences, 20(7), 490-499.

Kelso, J. S., \& Fuchs, A. (2016). The coordination dynamics of mobile conjugate reinforcement. Biological Cybernetics, 110(1), 41-53.

Klossek, U. M. H., Russell, J., \& Dickinson, A. (2008). The control of instrumental action following outcome devaluation in young children aged between 1 and 4 years. Journal of Experimental Psychology-General, 137(1), 39-51.

Kenward, B., Folke, S., Holmberg, J., Johansson, A., \& Gredebäck, G. (2009). Goal directedness and decision making in infants. Developmental Psychology, 45(3), 809. Kenward, B. (2010). 10-month-olds visually anticipate an outcome contingent on their own action. Infancy, 15(4), 337-361.

Lakens, D. (2013). Calculating and reporting effect sizes to facilitate cumulative science: A practical primer for t-tests and ANOVAs. Frontiers in Psychology, 4 , 863. 
Lewis, M., Alessandri, S. M., \& Sullivan, M. W. (1990). Violation of expectancy, loss of control, and anger expressions in young infants. Developmental Psychology, 26 (5), 745 .

Mele, A. R. (2000). Goal-directed action: Teleological explanations, causal theories, and deviance. Philosophical Perspectives, 14, $279-300$.

Meyer, M., \& Hunnius, S. (2021). Neural processing of self-produced and externally genera ted events in 3-month-old infants. Journal of Experimental Child Psychology, 204, Article 105039.

Miyazaki, M., Takahashi, H., Rolf, M., Okada, H., \& Omori, T. (2014). The image-scratch paradigm: A new paradigm for evaluating infants' motivated gaze control. Scientific Reports, 4(1), 1-6.

Pacherie, E. (2007). The sense of control and the sense of agency. Psyche, 13(1), 1-30.

Piaget, J. (1950). The psychology of intelligence. Routledge.

Rescorla, R. A. (1988). Behavioral studies of Pavlovian conditioning. Annual Review of Neuroscience, 11(1), 329-352.

Rochat, P., \& Morgan, R. (1995). Spatial determinants in the perception of self-produced leg movements in 3-to 5-month-old infants. Developmental Psychology, 31(4), 626.

Rochat, P., Morgan, R., \& Carpenter, M. (1997). Young infants' sensitivity to movement information specifying social causality. Cognitive Development, 12(4), 537-561.

Rochat, P., \& Striano, T. (1999). Emerging self-exploration by 2-month-old infants. Developmental Science, 2(2), $206-218$.

Rochat, P., \& Striano, T. (2000). Perceived self in infancy. Infant Behavior and Development, 23(3-4), 513-530.

Rochat, P. (2010). The innate sense of the body develops to become a public affair by 2-3 years. Neuropsychologia, 48(3), 738-745.

Rovee, C. K., \& Rovee, D. T. (1969). Conjugate reinforcement of infant exploratory behavior. Journal of Experimental Child Psychology, 8(1), 33-39.

Rovee-Collier, C. K., Morrongiello, B. A., Aron, M., \& Kupersmidt, J. (1978). Topographical response differentiation and reversal in 3-month-old infants. Infant Behavior and Development, 1, 323-333.

Rovee-Collier, C. K., Sullivan, M. W., Enright, M., Lucas, D., \& Fagen, J. W. (1980). Reactivation of infant memory. Science, $208(4448), 1159-1161$.

Russell, J. (1995). At two with nature: Agency and the development of self-world dualism. In J. L. Bermúdez, A. Marcel, \& N. Eilan (Eds.), The body and the self (pp. 127-152). MIT Press.

Russell, J. (1996). Agency: Its role in mental development. Taylor \& Francis Ltd.

Schmuckler, M. A. (1996). Visual-proprioceptive intermodal perception in infancy. Infant Behavior and Development, 19(2), 221-232.

Schmuckler, M. A., \& Fairhall, J. L. (2001). Visual-proprioceptive intermodal perception using point light displays. Child Development, 72(4), 949-962.

Sen, U., \& Gredebäck, G. (2021). Making the World Behave: A New Embodied Account on Mobile Paradigm. Frontiers in Systems Neuroscience, 15, Article 643526. Shepherd, J. (2014). The contours of control. Philosophical Studies, 170(3), 395-411.

Siqueland, E. R., \& Delucua, C. A. (1969). Visual reinforcement of nonnutritive sucking in human infants. Science, 165(3898), 1144-1146.

Sokol, B. W., Hammond, S. I., Kuebli, J., \& Sweetman, L. (2015). The development of agency. Handbook of Child Psychology and Developmental Science, 1-39.

Soska, K. C., \& Adolph, K. E. (2014). Postural position constrains multimodal object explora- tion in infants. Infancy, 19(2), $138-161$.

Synofzik, M., Vosgerau, G., \& Newen, A. (2008). I move, therefore I am: A new theoretical framework to investigate agency and ownership. Consciousness and Cognition, 17(2), 411-424.

Thelen, E., Corbetta, D., \& Spencer, J. P. (1996). Development of reaching during the first year: Role of movement speed. Journal of Experimental Psychology: Human Perception and Performance, 22(5), 1059-1076.

Thomas, R. L., Nardini, M., \& Mareschal, D. (2017). The impact of semantically congruent and incongruent visual information on auditory object recognition across development. Journal of Experimental Child Psychology, 162, 72-88.

van der Meer, A. L., Van der Weel, F. R., \& Lee, D. N. (1995). The functional significance of arm movements in neonates. Science, $267(5198), 693-695$.

von Hofsten, C., \& Lindhagen, K. (1979). Observations on the development of reaching for moving objects. Journal of Experimental Child Psychology, 28(1), 158-173.

von Hofsten, C. (1982). Eye-hand coordination in the newborn. Developmental Psychology, 18(3), 450.

von Hofsten, C. (1991). Structuring of early reaching movements: A longitudinal study. Journal of Motor Behavior, $23(4), 280-292$.

von Hofsten, C. (2004). An action perspective on motor development. Trends in Cognitive Sciences, 8(6), 266-272.

Watanabe, H., \& Taga, G. (2006). General to specific development of movement patterns and memory for contingency between actions and events in young infants. Infant Behavior and Development, 29(3), 402-422.

Watanabe, H., \& Taga, G. (2011). Initial-state dependency of learning in young infants. Human Movement Science, 30(1), $125-142$.

Wu, W. (2011). Attention as selection for action (p. 97). Attention: Philosophical and psychological essays.

Zaadnoordijk, L., Otworowska, M., Kwisthout, J., \& Hunnius, S. (2018). Can infants' sense of agency be found in their behavior? Insights from babybot simulations of the mobile- paradigm. Cognition, 181, 58-64.

Zaadnoordijk, L., Besold, T. R., \& Hunnius, S. (2019). A match does not make a sense: On the sufficiency of the comparator model for explaining the sense of agency. Neuroscience of Consciousness, 1, niz006.

Zaadnoordijk, L., Meyer, M., Zaharieva, M., Kemalasari, F., van Pelt, S., \& Hunnius, S. (2020). From movement to action: An EEG study into the emerging sense of agency in early infancy. Developmental Cognitive Neuroscience, 42, Article 100760.

Zmyj, N., Jank, J., Schütz-Bosbach, S., \& Daum, M. M. (2011). Detection of visual-tactile contingency in the first year after birth. Cognition, 1, 82-88. 